\title{
Effect of Solanum nigrum Linn against Lambda Cyhalothrin- Induced Toxicity in Rats
}

\author{
Marwa M Abd Elkawy ${ }^{1 *}$, Ghada Z A Soliman ${ }^{2 *}$, \\ Emam Abd-El Mobd'ea Abd-El Rehim ${ }^{3 *}$ \\ ${ }^{1}$ (BSc Agri Biochemistry; ${ }^{2} S$ Assist Prof Biochemistry; ${ }^{3}$ : Professor of Biochemistry, \\ National Nutrition Institute; ${ }^{* *}$ : Faculty of Agriculture, Cairo University
}

\begin{abstract}
Introduction: Lambda-cyhalothrin is a type II pyrethroid insecticide and may cause liver damage. Solanum nigrum may act as hepatoprotective agent; therefore we aimed to study the effect of solanum nigrum (dried fruits or its ethanolic extract) against lambda cyhalothrin toxicity in rats.

Materials and Methods: Thirty three male Sprague Dawlay rats were divided into 6 groups (G1: normal; G2 \& 3: normal treated with ethanolic extract of the dried fruits, and dried fruits respectively; G4: normal rats intoxicated with Lambda cyhalothrin; G5 \& 6: as G2 \& 3 but intoxicated with lambda cyhalothrin. At the end of the experiment ( 6 weeks), the rats were sacrificed and blood was taken for the determination of AST, ALT, Alk $P h, L D H, H b, H c t, M C H, M C H C$ and RBC count. Lactate dehydrogenase (LDH) was measured in serum and brain.

Results and Discusion: A significant decrease in body weight, Hb and Hct level was observed in G4 (Lambda cyhalothrin intoxicated rats). The intoxicated groups $(G 5 \& 6)$ treated with ethanolic extract or dried fruits of Solanum nigrum showed an improvement of body weight, $\mathrm{Hb}$ and Hct where a significant increase compared to G4 but still significantly lower than G1 was observed trying to return to normal or near normal level. A significant increase in AST, ALT and Alk Ph level was observed in G4. Group 5 \& 6 showed an improvement of AST, ALT and Alk Ph level where a significant decrease compared to G4, but still significantly higher than G1, was observed trying to return to normal or near normal.

Conclusion: Our results demonstrate that $S$. nigrum fruits or alcoholic extract was able to reverse the pathological parameters and may be useful as an antioxidant and hepatoprotective agent.
\end{abstract}

Key Words: Solanum nigrum, hepatoprotective, rats, lambda cyhalothrin.

\section{Introduction}

Pesticides have been used in agriculture to enhance food production by eradicating unwanted insects and controlling disease vectors. Among common used pesticides are the organophosphorus compounds (OP) [1]. Organophosphate insecticides induced toxic effects causing damage to various membranous components of the cell. Pyrethroids are widely used in field pest control and household use as well as veterinary medicine and are among the most potent insecticides known [2]. The widespread use of these pesticides consequently leads to the exposure of manufacturing workers, field applicators, the ecosystem, and finally the public to the possible toxic effects of these pesticides. Lambda-cyhalothrin is a type II pyrethroid used predominantly on cattle and sheep and to a lesser extent in pigs and goats for the control of a broad range of ectoparasites.

Lambda cyhalothrin belongs to the chemical family synthetic pyrethroid insecticide. The low toxicity of pyrethroid insecticides to mammals and birds and limited soil persistence has encouraged their widespread application in agriculture as potent agents against pests [3]. $\lambda$-cyhalothrin has been observed to exert significant genotoxic and cytotoxic effects on human lymphocytes cultured in vitro [4], a dose dependent chromosomal aberrations in mice [5] and changes in rabbit peripheral blood lymphocytes [6].

Solanum nigrum (family: Solanacae), commonly called Black nightshade or deadly nightshade, known as Enab Eldib here in Egypt, grows as a weed, found in the dry parts of India and other parts of the world [7]. It grows nearly everywhere in Africa and America. Solanum nigrum is a common herb that grows wildly and abundantly in open fields [8].

S. nigrum has a medicinal usage and has been used as a traditional folk medicine for treating various ailments such as pain, fever, inflammation, cough, asthma, wounds, ulcers [9], leprosy, skin diseases, hemorrhoids, dropsy and liver disorders [10], anticancer [10], antioxidant [11], hepatoprotective agent [12], neuroprotective [13], cytoprotective [14], antimicrobial [15], antinociceptive and antipyretic properties [16]. It has been claimed that Solanum nigrum are an excellent remedy for liver disorders [10].

Alpha $(\alpha)$, beta $(ß)$ and gamma $(\gamma)$ carotenase, lutein, lycopene, crytoxanthine, vitamin $C$, glucose, fructose solasodine, tomatidenol, tigogenin, solamargine and solasonine are the main constituents in aerial parts of this plant. S. nigrum possesses various compounds that are responsible for diverse activities. The major active 
components are glycoalkaloids, glycoproteins, and polysaccharides. It also contains polyphenolic compounds such as gallic acid, catechin, protocatechuic acid (PCA), caffeic acid, epicatechin, rutin, and naringenin [17].

\section{Plant Materials}

\section{Materials And Methods}

S. nigrum, whole plant, was collected from the garden of faculty of agriculture, Cairo University in Egypt and authenticated by the botanists in the faculty of agriculture, Cairo University.

\section{Chemicals}

Lambda Cyhalothrin is a synthetic pyrethroid insecticide $\left(\mathrm{C}_{23} \mathrm{H}_{19} \mathrm{ClF}_{3} \mathrm{NO}_{3}\right)$. Its CAS chemical name is ( $\alpha$-cyano-3-phenoxy -benzyl-3-(2-chloro-3, 3, 3-trifluoro-1-propenyl)-2, 2-dimethylcyclopropanecarboxylate). All other chemical were AR.

\section{Ethanolic Extracts}

The powdered plant tissue was collected, dried and grinded, and then it was soxhlet extracted successfully with $70 \%$ ethanol followed by the complete removal of solvent and the final yield was $15 \%$ of the original. Then it was lyophilised.

$\mathbf{L D}_{\mathbf{5 0}}: \mathrm{LD}_{50}$ value of ethanol extract of the fruits of $S$. nigrums was found to be $2 \mathrm{~g} / \mathrm{kg} \mathrm{BW}$ [18], while $\mathrm{LD}_{50}$ value of lambda cyhalothrin was found to be $79 \mathrm{mg} / \mathrm{kg}$ BW $[\mathbf{1 9}, \mathbf{2 0}]$.

ANIMALS: Thirsty three male Sparage-Dawlay rats, weighing around $200 \mathrm{~g}$, were maintained under standard environmental conditions and fed a standard diet, water was supplied ad libitum. The diets were prepared according to 21, 22. The rats were fed on the standard diet for 10 days before beginning of the experiment as adaptation period.

DOSE: Rats were intoxicated orally with lambda-cyhalothrin and the dose was $1 / 20$ of $\operatorname{LD}_{50}$ every 2 consecutive days intervals (modified from 23, 24]. Lambda cyhalothrin was dissolved in oil.

\section{Experimental Protocol}

Thirty Three (33) Rats Were Divided into 6 groups (5 or 6 rats/group). Group 1 (G 1: normal, -ve, control): fed on standard diet; Group 2 (G 2) normal rats fed on control diet supplemented with ethanolic extract of dried fruits (5\% w/w); Group 3 (G3) normal rats fed on control diet supplemented with dried fruits $(5 \% \mathrm{w} / \mathrm{w})$, Group 4 (G 4: intoxicated, +ve, control): fed on standard diet and intoxicated with lambda cyhalothrin; Group 5 (G 5) normal rats fed on control diet supplemented with ethanolic dried fruits $(5 \% \mathrm{w} / \mathrm{w})$ and intoxicated with lambda cyhalothrin; Group 6 (G 6) normal rats fed on control diet supplemented with dried fruits (ethanolic extracts of 5\% w/w) and intoxicated with lambda cyhalothrin, The experiment lasted for 6 weeks (45 days).

At the end rats were fasted overnight, and blood was collected from the orbital plexus of anaesthetized rats for serum or plasma analysis and haematological examination. The serum or plasma were separated and kept at $20^{\circ} \mathrm{C}$ until further analysis. Liver was removed, washed with saline, and then weighed.

\section{Biochemical Methods}

Serum alanine amino transferase (ALT) and aspartate amino transferase (AST) activities were measured by the method of [25]. Serum alkaline phosphates (ALK PH) activity was estimated according to the method of [26] and lactate dehydrogenase activity (LDH) was estimated by the method of [27] (kits of Pointe Scientific, Canton, USA). Relative liver weight (RLW) were calculated as follows: RLW=[( liver weight/ final body weight, $\left.\mathrm{FBW})^{*} 100\right]$.

\section{Tissue (Brain) Preparation}

Brain was rinsed in phosphate buffered saline ( $\mathrm{pH} \mathrm{7.4)} \mathrm{to} \mathrm{remove} \mathrm{blood,} \mathrm{and} \mathrm{then} \mathrm{homogenized} \mathrm{in} 5$ $\mathrm{mL}$ buffer containing $100 \mathrm{mM}$ potassium phosphate ( $\mathrm{pH}$ 7.0) and $2 \mathrm{mM}$ EDTA, per gram tissue (brain). Centrifuge at $10,000 \mathrm{x}$ g for $15 \mathrm{~min}$ at $4^{\circ} \mathrm{C}$ and the supernatant was kept at $-20^{\circ} \mathrm{C}$ for assay.

\section{Haematological Methods}

Hemoglobin (Hb) was measured using the cyanomethaemoglobin method using Randox kits, Randox: Laboratories, USA [28]. Hematocrite (Hct) was measured by centrifugation of blood collected into heparinized microcapillary tubes no. 563 supplied by Bio Merieux [29]. Hematocrite was calculated using the equation: Hct $=$ length of red cell column $(\mathrm{mm}) /$ length of total column $(\mathrm{mm})$. Red blood cells count (RBCs) was counted manually [30]. Mean cell hemoglobin concentration $(\mathrm{MCHC})$ was calculated using the equation: $\mathbf{M C H C}=$ $\left[\left(\mathrm{Hb}^{*} 100\right) / \mathrm{Hct}\right]$. Mean cell hemoglobin $(\mathrm{MCH})$ was calculated using the equation: $\mathbf{M C H}=\left[\left(\mathrm{Hb}^{*} 10\right) / \mathrm{RBC}\right]$. Mean red cell volume (MCV) was calculated using the equation: MCV $=\left[\left(\mathrm{Hct}^{*} 10\right) / \mathrm{RBC}\right][\mathbf{3 0}]$. 


\section{Histopathological Methods}

Immediately following sacrifice of the rats, part of the livers were collected and fixed in $10 \%$ formalin, embedded in paraffin wax, sectioned at $5 \mathrm{u} \mathrm{m}$ and stained with haematoxylin and eosin (H\& E).

\section{Statistical Analysis}

The statistical significance of the data was calculated using the Student's t-test. Data were expressed as means \pm SEM for control and experimental animals. The data were analyzed using one way analysis of variance (ANOVA) followed by post hock Duncan's test using SPSS v 11 (statistical package for social sciences). The results were considered statistically significant if the $\mathrm{P}<0.05$.

\section{Body Weight,}

\section{Results}

The body weight such as Initial, Final and Weight gain (IBW, FBW and BWG), liver weights and relative liver weight (RLW) of control and experimental rats are shown in Table I. At the beginning rats' weight were matched (comparable) with no significant differences. The body weight was found to be significantly reduced in lambda cyhalothrin treated rats $(\mathrm{G} 4)$ whereas lambda cyhalothrin intoxicated groups treated with Solanum nigrum (fruits or ethanolic extract, $\mathrm{G} \mathrm{5,6)} \mathrm{showed} \mathrm{also} \mathrm{significant} \mathrm{body} \mathrm{weight} \mathrm{reduction} \mathrm{but} \mathrm{the}$ reduction is less than $\mathrm{G} 4$, i.e. body weight begins to improve. Normal rats treated with ethanolic extract or dried fruits (G 2 \& 3) showed no significant change.

Intoxication of the rats with lambda cyhalothrin resulted in enlargement of liver with pale reddish brown in colour. The group treated with dried fruits or ethanol extract of dried fruits of $S$. nigrum $(\mathrm{G} 2,3)$, showed liver size, which was similar to that found in the normal rats. However, a significant $(\mathrm{P}<0.001)$ restoration in liver weight was obtained in intoxicated groups treated with dried fruits or ethanol extract of dried fruits of S. nigrum (Fig. 1) but still significantly higher than normal control (G 1). The liver and liver to body weight ratio was found to be significantly increased in rats intoxicated with lambda cyhalothrin (G 4) or lambda cyhalothrin intoxicated rats treated with $S$. nigrum fruits or alcoholic extract (G 5,6). The increase in G 5, 6 was less than $\mathrm{G} 4$ where liver to body weight ration begin to decrease trying to return to normal ratio as normal control. Normal rats treated with $S$. nigrum fruits or alcoholic extract $(\mathrm{G} \mathrm{2,3)} \mathrm{showed} \mathrm{no} \mathrm{significant} \mathrm{change} \mathrm{as}$ compared to control (Table I).

\section{Haematological Changes}

The values of $\mathrm{Hb}$, Hct and MCHC; and RBC count were significantly decreased $(\mathrm{P}<0.05$ to 0.001$)$ after lambda cyhalothrin administration (G 4) and returned to normal following dried fruits of S. nigrum or ethanol extract of dried fruits of S. nigrum administration (Groups 5 and 6). The decrease reach in RBC count $(15.75 \%, \mathrm{P}<0.01), \mathrm{Hb}$ content $(16.47 \%, p<0.001)$ and $\mathrm{Ht}(33 \%, \mathrm{P}<0.001)$ in Lambda cyhalothrin treated group compared to those of control group (G1). The Hct values did not change in Groups 1 to 3 (Table II).

\section{Liver Function}

The activities of hepatic marker enzymes in control and experimental groups were shown in Table III. The results of biochemical parameters revealed the elevation of activities of hepatic enzymes marker levels in lambda cyhalothrin treated group (G 4) indicating that lambda cyhalothrin induced damage to the liver (Table III). A significant $(p<0.001)$ reduction was observed in AST, ALT and ALK Ph in the group treated with dried fruits of S. nigrum or treated with ethanol extract of dried fruits of S. nigrum in comparison with G4 (rats intoxicated with lambda cyhalothrin). The enzyme levels were almost restored to the normal levels found in control. Also groups treated only with dried fruits of $S$. nigrum or treated with ethanol extract of dried fruits of S. nigrum showed no significant change in AST, ALT and ALK Ph activity.

\section{Ldh In Serum And Brain}

In lambda cyhalothrin treated group (G 4), LDH activity in brain was significantly decreased by $37.45 \%$ ( $\mathrm{p}$ <.01) compared to control group, with significant increase of its level in serum of $\mathrm{G} 4$ (lambda cyhalothrin treated group) by $34.7 \%$. Administration of dried fruits of S. nigrum or ethanol extract of dried fruits of S. nigrum ameliorated LDH activity in both serum and brain. No significant change was observed in normal rats group (G $2 \& 3)$ treated with dried fruits of S. nigrum or ethanol extract of dried fruits of S. nigrum.

\section{Discussion}

The present study showed that rats exposed to lambda cyhalothrin, a pyrethroid type II insecticide, induced a marked decrease in food consumption and body weight of lambda cyhalothrin-treated rats (G 4) which agree with $(\mathbf{3 1}, \mathbf{3 2}$ ] whom they found similar results in animals exposed to different pyrethroid compounds as Delta-methrin and fenvalerate and also agree with (33] using $\mathrm{CCl}_{4}$ as chemical induced liver damage. The alteration of appetite due to lambda cyhalothrin exposure may account for the reduction of food 
intake seen in the lambda cyhalothrin rats. Our results, also, agree with $[\mathbf{3 4}, \mathbf{3 1}, \mathbf{3 2}]$ where they found a significant decrease in final body weight but in their study the rats were intoxicated with ethanol and agree also with (33] but their rats were intoxicated with $\mathrm{CCl}_{4}$. Also, our results agree with [35] whom reported that lambda-cyhalothrin showed signs of toxicity as reduction in food intake, diarrohea, suppression in body weight gain, ataxia, lethargy, sedation, haemotoxicity. Moreover, previous studies also showed a decrease in these parameters in rabbits treated with cypermethrin [36].

Our results showed a significant increase in the ratio between the liver weight and final body weight in lambda cyhalothrin intoxicated rats. This ratio begin to significantly decreased in treated groups ( $G 5 \& 6$ ) when compared with G 4 but still significantly higher than normal control or their respective control (G 5 vs 2 and G 6 vs 3). This protective effect may be due to the presence of nutrients and polyphenols present in Solanum nigrum fruits [37) which might have detoxified the liver and improved the body weight to near normal levels. Our results agree with $[\mathbf{9}, \mathbf{3 4}]$ where they found significant body reduction and increased liver-body weight ratio but in their experiment they fed rats with ethanol as chemical induced-hepatotoxicity when compared with the controls. Our results disagree with [38] where they found a significant decrease in relative liver weight in lambda cyhalothrin intoxicated rats.

Rats exposed to lambda cyhalothrin showed decreased haematological parameters (RBCs, Hct and $\mathrm{Hb}$ ) and developed anaemia in rats which is indicative of liver dysfunction. The histopathological images taken for the test groups (Groups 5 and 6) demonstrated less damage than in lambda cyhalothrin treated group indicating hepatoprotective effects of the dried Solanum nigrium fruits or its alcoholic extract. Our results are in agreement with previous reports which demonstrated that pyrethroid insecticide exposure altered hematological parameters in rats [39], in dogs [40], in the freshwater fish [41] and in rats [42] using $\mathrm{CCl}_{4}$ as chemical inducing liver damage. The significant reduction in RBCs and $\mathrm{Hb}$ might be due probably to the inhibition of erythropoiesis and hemosynthesis, and to an increase in the rate of erythrocyte destruction in hemopoietic organs. On the other hand, haemoglobin in erythrocytes, is a major source of radical production when it interacts with redox drugs or xenobiotics [43] giving rise to superoxide radicals, hydrogen peroxide and in certain cases peroxy radicals leading to membrane lipid peroxidation and hemolysis [44].

The efficacy of any hepatoprotective drug is essentially dependent on its ability in reducing the harmful effects or maintaining the normal hepatic physiology that has been disturbed by a hepatotoxin. Generally, hepatic cells take part in a variety of metabolic actions and restrain a host of enzymes. Previous studies have demonstrated that pesticides, due to their hydrophobic nature, were largely accumulated in the biological membrane especially in the phospholipid bilayers [45] and in lipid-rich internal tissues including body fat, skin, liver, kidney, ovaries and elements of the central and peripheral nervous system [46]. Liver was the major site of pyrethroid metabolism which accumulated a great concentration of its metabolites [47]. Their toxic effects occurred probably through generation of reactive oxygen species causing damage to various membranous components of the cell. Rats treated with cyhalothrin (G 4) developed significant hepatic damage as evidenced by substantial increases in the serum activities of ALT, AST and ALK Ph that are indicators of cellular leakage and loss of functional integrity of cell membrane in liver [48, 49]. During liver injury, transport function of the hepatocytes is disturbed which leads to leakage of plasma membrane, thereby causing an increased enzyme level in serum [50]. In our study, we observed a significant increase in the activities of liver marker enzymes such as AST, ALT, and ALK PH, on lambda cyhalothrin intoxicated rats, which indicates increased permeability, damage and/or necrosis of hepatocytes [51]. In the present study, administration of dried S. nigrum fruits or its ethanolic extract decreased the lambda cyhalothrin induced elevated enzyme levels in group $5 \& 6$ to near normal. This suggests the maintenance or stabilization of structural integrity of hepatocytic cell membrane or regeneration of damaged liver cells by the extract $[\mathbf{3 3}, \mathbf{5 2}]$. Our results agree with $[\mathbf{1 8 , 5 3}]$ where they found a significant increase in AST, ALT and ALK PH levels in rats but their rats were intoxicated with ethanol or $\mathrm{CCl}_{4}$. The histopathological changes revealed less damage in the treated G 5 and 6 compared to the lambda cyhalothrin intoxicated rats [G 4). This therefore indicates some protective effect of the $S$. nigrum fruits or alcoholic extract extract.

The increase of LDH activity, marker of hemolysis [54] levels in erythrocytes suggested that anemia signs, observed in our study, are related to intravascular hemolysis. Similar results have been found in rat erythrocytes exposed to cypermethrin for 2 months [55].

Lactate deshydrogenase (LDH), a tetrameric enzyme, was recognized as a potential marker for assessing the toxicity of drugs and xenobiotics. The significant decline of LDH activity in brain of rats intoxicated with lambda cyhalothrin (G 4) compared to normal control group suggested the decrease in the glycolytic process due to the lower metabolic rate as a result of LTC intoxication. Several reports revealed a decreased LDH activity in tissues under various pesticide toxicity conditions [56]. Co-administration of dried $S$. nigrum fruits or its ethanolic extract to LTC-treated group improved LDH activity in brain and this may be due to enhancement of glycolysis. 


\section{Conclusion:}

Our results demonstrate that $S$. nigrum fruits or alcoholic extract was able to reverse the pathological parameters and serum levels of ALT, AST and ALK PH of liver damage. This protecting ability of S. nigrum fruits or alcoholic extract may be due to, at least partially, to the high content of polyphenols, alkaloids and saponins in SNE. Therefore, dietary $S$. nigrum fruits or alcoholic extract may be useful as a hepatoprotective agent against lambda cyhalothrin induced liver damage in vivo.

\section{Reference:}

[1] Mea Elhalwagy, Em Darwish And Ns Zaher. Prophylactic Effect of Green Tea Polyphenols against liver and kidney injury induced by fenitrothion insecticide. Pest Biochem Physiol., 91, 2008, 81-89.

[2] AD Righi and J Palermo-Neto. Behavioral effects of type II pyrethroid cyhalothrin in rats. Toxicol Appl Pharmacol., 191, 2003, 167-176.

[3] AH Glickman and JJ Lech. Differential toxicity of trans-permethrin in rainbow trout and mice. II. Role of target organ sensitivity. Toxicol Appl Pharmacol., 66, 1982, 162-171.

[4] R Naravaneni and K Jamil. Evaluation of cytogenetic effects of lambda-cyhalothrin on human lymphocytes. Journal of Biochemical and Molecular Toxicology, 19(5), 2005, 304-310.

[5] LKS Chauhan, S Chandra, PN Saxena and SK Gupta. In vivo cytogenetic effects of a commercially formulated mixture of cypermethrin and quinalphos in mice. Mutation Research Genetic Toxicology and Environmental Mutagenesis, 587(1-2), 2005, 120125.

[6] SV Georgieva. Investigation of the cytogenetic effect of the insecticide karate on rabbit peripheral blood lymphocytes. Trakia Journal of Sciences, 4(2), 2006, 34-38.

[7] FN Mbagwu, CU Nwachukwu and OO Okoro. Root Anatomical Studies on Solanum Macrocarpum and Solanum nigrum (Solanaceae). Journal of American Science, 3(3), 2007, 234-238

[8] Kiran, R Kudesia, M Rani, and A Pal. Reclaiming degraded land in India through the cultivation of medicinal plants. Bot Res Int., 2, 2009, 174-181.

[9] V Arulmozhi, M Krishnaveni, K Karthishwaran, G Dhamodharan, and S Mirunalini. Antioxidant and antihyperlipidemic effect of Solanum nigrum fruit extract on the experimental model against chronic ethanol toxicity. Pharmacognosy Magazine, 6 (21), 2010, $42-50$.

[10] ZA Zakaria, HK Gopalan, H Zainal, et al. Antinociceptive, anti-inflammatory and antipyretic effects of Solanum nigrum chloroform extract in animal models. Yakugaku Zasshi., 126, 2006, 1171-1178.

[11] AQ Tarique, MZ Sayeed, S Moyad, S Ghassan and B Nahid. Effect of Solanum nigrum on Immobilization stress induced antioxidant defence changes in rat. Research journal of biological sciences, 3(12), 2008, 1426-1429.

[12] HF Huseini, SM Alavian, R Heshmat, MR Heydari and K Abolmaali. The effect of Liv-25 on liver cirrhotic parients: a randomized, double-blind, placebo controlled first approach. Phytomedicine, 12, 2005, 619-624.

[13] RM Perez, JA Perez, LMD Garcia and HM Sosa. Neuropharmacological activity of Solanum nigrum fruit. Ethnopharmaco., 62(I), 1998, 43-48.

[14] KV Prashant, S Shasidhara, MM Kumar and Sridhar. Cytoprotective role of S. nigrum against gentamicin- induced Kidney cell damage. Fitoterapia, 72, 2001, 481-486.

[15] M Jainu and CS Shayamala Devi. Antioxidant effect of methanolic extract of Solanum nigrum berries on aspirin induced gastric muscosal injury. Indian Journal of Clinical Biochemistry, 19(1), 2004, 57-61.

[16] P Rani and N Khullar. Antimicrobial evaluation of some medicinal plants for their anti-enteric potential against multi drug resistant Salmonella typhi. Phytother Res., 18(8), 2004, 670-673.

[17] M Sikdar and U Dutta. Traditional phytotherapy among the Nath people of Assam. Ethno Med., 2, 2008, 39-45.

[18] K Raju, G Anbuganapathi, V Gokulakrishnan, B Rajkapoor, JB Balasundarm, and S Maniand. Effect of Dried Fruits of Solanum nigrum LINN against $\mathrm{CCl}_{4}$-Induced Hepatic Damage in Rats. Biol. Pharm. Bull., 26 (11), 2003, 1618-1619.

[19] H Kidd and DR James. The agrochemicals Handbook. $3^{\text {rd }}$ edn, 1991. Royal Society of Chemistry Information Services, Cambridge, UK., 27-33.

[20] EPA: Environmental Protection Agency. Fact Sheet Number 171: Karate. Washington, DC, 1988; p321.

[21] National Research Council Committee on Animal Nutrition. Nutrient requirement of laboratory animals. No. $103^{\text {rd }}$ revised edition. National academy of science, National Research Council, Washington, DC, 1978.

[22] PG Reeves, FH Nielson, and Jr Fahey GC. Ain 93 Purified diets for laboratory rodents: Final report of the American Institute of Nutrition and HOC Wriling Committee on the Reformation of the Ain 76 A rodent diet. J. Nutr., 123, 1993, 1939-1952.

[23] A Ḉelik, B Mazmanci, Y Çamlica, A Askin and U Çőmelekoglu. Cytogenitic effects of lambda-cyhalothrin on wistar rat bone marrow. Mutat Res., 2003, 539, 91-97.

[24] A Ḉelik, B Mazmanci, Y Ḉamlica, U Çómelekoglu and A Askin. Evaluation of cytogenetic effects of lambda-cyhalothrin on Wistar rat bone marrow by gavage administration. Ecotoxicol Environ Saf., 61, 2005, 128-133.

[25] S Reitman and S Frankel. Colorimetric method for the determination of serum glutamic oxalacetic and glutamic pyruvic transaminases. Am J Clin Pathol., 28, 1957, 56-63.

[26] NW Tietz et al. clinical guide to laboratory tests, 3rd Ed AACC press, 1995

[27] NW Tietz. Fundamentals of Clinical Chemistry, 2nd Ed., Philadelphia, W.B.Saunders Co., P. 657, 1976.

[28] JU Dacie and SM Lewis. Basic hematology techniques. In: Dacie JU, Lewis SM (Eds). Practical hematology. Churchill Livingston: London. 1975, pp 21-96.

[29] RA Mciniory. A microhematocrite for determining Packed Cell and haemoglobin concentration on capillary blood. J. Clinc. Pathol., 7,1954, 32-36.

[30] Monica Cheesbrough. District laboratories practice in tropical countries. Part 2. Cambridge Low-Price Eddition, 2004, PP: 308-318.

[31] K Prasanthi, R Muralidhara, and PS Rajini. Fenvalerate-induced oxidative damage in rat tissues and its attenuation by dietary sesame oil. Food Chem. Toxicol., 4, 2005, 299-306.

[32] E Kilian, R Delport, MS Bornman, and $\mathbf{C}$ de Jager. Simultaneous exposure to low concentrations of dichlorodiphenyltrichloroethane, deltamethrin, nonylphenol and phytoestrogens has negative effects on the reproductive parameters in male Sprague-Dawley rats. Andrologia, 39, 2007, 128-135.

[33] HM Lin, HC Tseng, CJ Wang et al. Hepatoprotective effect of Solanum nigrum Linn extract against $\mathrm{CCl}_{4}$ induced oxidative damage in rats. Chem Biol Int., 171, 2008, 283-293. 
[34] V Arulmozhi, M Krishnaveni and S Mirunalini. Protective effect of Solanum nigrum fruit extract on the functional status of liver and kidney against ethanol Induced Toxicity. J Biochem Tech (2011) 3(x): xxx-xxx. (Article in press).

[35] WD Ratnasooriya, SSK Ratnayake and Jayatunga. Effects of pyrethroid insecticide ICON (lambda cyhalothrin) on reproductive competence of male rats. Asian J Androl., 4(1), 2002, 35-41.

[36] MI Yousef, GA Abdallahand, KI Kamel. Effect of ascorbic acid and vitamin E supplemintation on semen quality and biochemical parameters of male rabbits. Anim Reprod Sci., 7, 2003, 99-111.

[37] SE Potawele, SD Sinha, KK Shroff et al. Solanum nigrum Linn: A phytochemical review. Pharmacol Online, 3, 2008, 140-163.

[38] H Fetoui, El-M Garouia, and N Zeghal. Lambda-cyhalothrin-induced biochemical and histopathological changes in the liver of rats: Ameliorative effect of ascorbic acid. Experimental and Toxicologic Pathology, 61, 2009, 189-196.

[39] CM Parker, VJ Piccirillo, SL Kurtz, FM Garner, TH Gardiner and GA Van Gelder. Six-month feeding study of fenvalerate in dogs. Fundam Appl Toxicol., 4, 1984, 577-586.

[40] S Manna, D Battacharyya, TK Mandal and S Das. Repeated dose toxicity of alfa-cypermethrin in rats. J Vet Sci., 5, 2004, 241245.

[41] S Adhikari, B Sarkar, A Chatterjee, CT Mahapatra and S Ayyappan. Effects of cypermethrin and carbofuran on certain haematological parameters and prediction of their recovery in a freshwater teleost, Labeo rohita (Hamilton) Ecotoxicol Environ Saf., $58,2004,220-226$.

[42] RAM Elhag, SMA EI Badwi, AO Bakhiet and M Galal1. Hepatoprotective activity of Solanum nigrum extracts on chemically induced liver damage in rats. Journal of Veterinary Medicine and Animal Health, 3 (4), 2011, 45-50.

[43] JK French, CC Winterbourn and RW Carrel. Mechanism of oxyhaemoglobin breakdown on reaction with acetyl phenyl hydrazine. Biochem J., 17, 1978, 19-26.

[44] R Clemens and HD Waller. Lipid peroxidation in erythrocytes. Chem Phys Lipids, 45, 1987, 251-268.

[45] A Lee, J East, and P Balagaug. Interactions of insecticides with biological membranes. Pestic Sci., 32, 1991, $317-327$.

[46] DM Soderlund, JM Clark, LP Sheets, LS Mullin, VJ Piccirillo, D Sargent, et al. Mechanisms of pyrethroid neurotoxicity: implications for cumulative risk assessment. Toxicology, 171, 2002, 3-59.

[47] Giray B, Gurbay A, and Hincal F. Cypermethrin-induced oxidative stress in rat brain and liver is prevented by vitamin E or allopurinol. Toxicol Lett., 118, 2001, 139-146.

[48] RB Drotman, and GT Lawhorn. Serum enzymes as indicators of chemical induced liver damage, Drug Chem. Toxicol., 1, 1978, $163-171$.

[49] PK Mukherjee. Plant products with hypocholesterolemic patientials, Adv Food Nutr Res., 47, 2003, 277-338.

[50] A Jadon, M Bhadauria, and S Shukla. Protective effect of Terminalia belerica Roxb. and gallic acid against $\mathrm{CCL}_{4}$ induced damage in albino rats. J Ethnopharmacol., 109, 2007, 214-218.

[51] J Sathiavelu, GJ Senapathy, R Devaraj et al. Hepatoprotective effect of chrysin on prooxidant-antioxidant status during ethanol induced toxicity in female albino rats. J Phar Pharmacol., 61, 2009, 809-817.

[52] CC Hsieh, HL Fang, WC Lina. Inhibitory effect of Solanum nigrum on thioacetamide-induced liver fibrosis in mice. J Ethanopharmacol., 119, 2008, 117-121.

[53] H Fetoui, El-M Garouia, M-A Fatma, and N Zeghal. Oxidative stress induced by lambda-cyhalothrin (LTC) in rat erythrocytes and brain: Attenuation by vitamin C. Environmental Toxicology and Pharmacology, 26, 2008, 225-231.

[54] GJ Kato, V McGowan, RF Machado, JA Little, J Taylor, CR Morris, S James, NX Wang, M Poljakovic, SM Morris and MT Gladwin. Lactate dehydrogenase as a biomarker of hemolysis-associated nitric oxide resistance, priapism, leg ulceration, pulmonary hypertension, and death in patients with sickle cell disease. Blood, 107, 2006, 2279-2285.

[55] R Gabbianelli, G Falcioni, C Nasuti and F Cantalamessa. Cypermethrin-induced plasma membrane perturbation on erythrocytes from rats: reduction of fluidity in the hydrophobic core and in glutathione peroxidase activity. Toxicology, 175, 2002, 91-101.

[56] R Mishra and SP Shukla. Endosulfan effects on muscle malate dehydogenase of the freshwater catfish Clarias batrachus. Ecotoxicol Environ Saf., 56, 2003, 425-433.

\begin{tabular}{|c|c|c|c|c|c|c|c|}
\hline \multicolumn{2}{|c|}{ Table (1): Effect of Solanum nigrum on initial body weight (IBW), final body weight (FBW) and body weight gain } \\
(BWG) of rats exposed to lambda cyhalothrin.
\end{tabular}

G1: Control, G2: normal + S. nigrum Extract, G3: Normal + S. nigrum Fruit, G4: Control+ Lambda cyhalothrin, G5: normal+ S. nigrum Extract +Lambda cyhalothrin, G6: Normal+ S. nigrum Fruit+ Lambda cyhalothrin; a: G1, b: G2, c: G3 , d: G4, e: G5; Significance of $\mathrm{P}<0.01$.

\begin{tabular}{|c|c|c|c|c|c|c|c|}
\hline $\begin{array}{c}\text { Group } \\
\mathrm{s}\end{array}$ & $\begin{array}{l}\text { No. of } \\
\text { rats in } \\
\text { groups }\end{array}$ & $\begin{array}{c}\mathrm{Hb} \\
(\mathrm{gm} / 100 \mathrm{ml})\end{array}$ & $\begin{array}{c}\mathrm{Hct} \\
(\mathrm{gm} / 100 \mathrm{ml})\end{array}$ & $\mathrm{RBC}^{*} 10^{\wedge} 6$ & $\mathrm{MCHC}$ & $\mathrm{MCV}$ & $\mathrm{MCH}$ \\
\hline
\end{tabular}


Effect of Solanum nigrum Linn against Lambda Cyhalothrin-Induced Toxicity in Rats

\begin{tabular}{|c|c|c|c|c|c|c|c|}
\hline 1 & 6 & $14.21 \pm 0.35$ & $43.62 \pm 1.04$ & $6.16 \pm 0.22$ & $32.57 \pm 0.02$ & $71.29 \pm 3.26$ & $23.22 \pm 1.07$ \\
\hline 2 & 5 & $14.00 \pm 0.37$ & $43.00 \pm 1.11$ & $6.00 \pm 0.28$ & $32.56 \pm 0.02$ & $72.49 \pm 4.55$ & $23.60 \pm 1.49$ \\
\hline 3 & 6 & $14.05 \pm 0.36$ & $43.14 \pm 1.07$ & $6.13 \pm 0.19$ & $32.56 \pm 0.02$ & $70.62 \pm 2.45$ & $22.99 \pm 0.81$ \\
\hline 4 & 5 & $\begin{array}{c}11.87 \pm 0.31^{\mathrm{a}, \mathrm{b}} \\
, \mathrm{c}\end{array}$ & $36.61 \pm 0.93^{\mathrm{a}, \mathrm{b}, \mathrm{c}}$ & $\begin{array}{c}5.19 \pm 0.08 \\
\mathrm{a}, \mathrm{b}, \mathrm{c}\end{array}$ & $32.42 \pm 0.02$ & $70.63 \pm 1.88$ & $22.90 \pm 0.62$ \\
\hline 5 & 5 & $13.23 \pm 0.34^{\mathrm{d}}$ & $40.70 \pm 1.01$ & $5.46 \pm 0.12^{\mathrm{a}, \mathrm{c}}$ & $32.51 \pm 0.02$ & $74.68 \pm 2.50$ & $24.28 \pm 0.83$ \\
\hline 6 & 6 & $13.46 \pm 0.25^{\mathrm{d}}$ & $40.80 \pm 0.88$ & $\begin{array}{c}5.35 \pm 0.12^{\mathrm{a}, \mathrm{b}} \\
, \mathrm{c}\end{array}$ & $32.51 \pm 0.02$ & $76.45 \pm 2.68$ & $24.86 \pm 0.88$ \\
\hline
\end{tabular}

G1: Control, G2: normal + S. nigrum Extract, G3: Normal + S. nigrum Fruit, G4: Control+ Lambda cyhalothrin,

G5: normal+ S. nigrum Extract +Lambda cyhalothrin, G6: Normal+ S. nigrum Fruit+ Lambda cyhalothrin; a: G1,

b: G2, c: G3 , d: G4, e: G5; Significance of P $<0.01$.

\begin{tabular}{|c|c|c|c|c|c|l|}
\hline \multicolumn{6}{|c|}{ Table (III): Effect of Solanum nigrum on Alk. Phosphatase, AST and ALT of rats exposed to Lambda } \\
cyhalothrin.
\end{tabular}

G1: Control, G2: normal + S. nigrum Extract, G3: Normal + S. nigrum Fruit, G4: Control+ Lambda cyhalothrin,

G5: normal+ S. nigrum Extract +Lambda cyhalothrin, G6: Normal+ S. nigrum Fruit+ Lambda cyhalothrin; a: G1,

b: G2, c: G3, d: G4, e: G5; Significance of P < 0.01 .

\begin{tabular}{|c|c|c|}
\hline \multicolumn{3}{|c|}{ Figure 1a-f: Histopathological changes of rats exposed to lambda cyhalothrin } \\
\hline 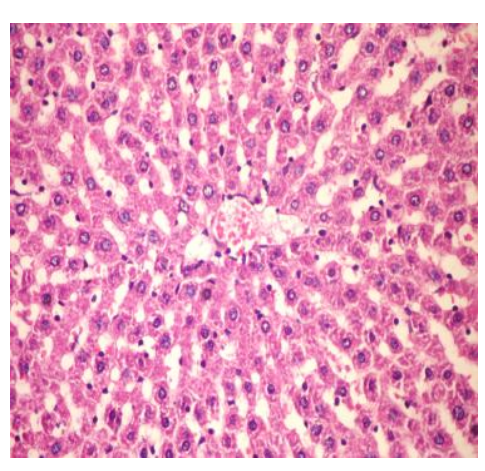 & 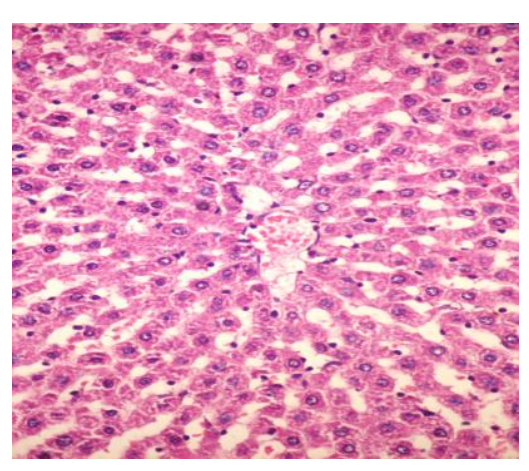 & 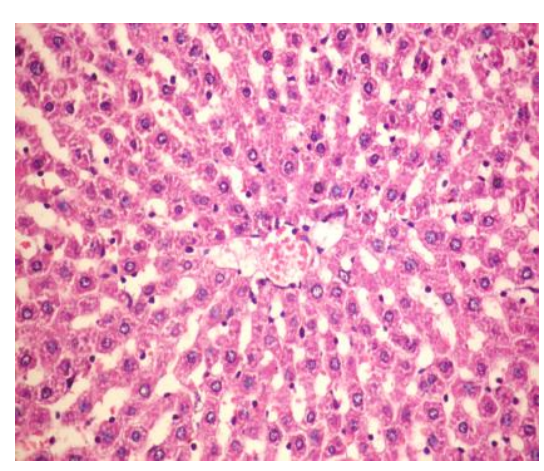 \\
\hline $\begin{array}{l}\text { Fig 1a: Liver of rat from group } \\
1 \text { 9normal control) showing the } \\
\text { normal histological structure of } \\
\text { hepatic lobule (H \& E X 400). }\end{array}$ & $\begin{array}{l}\text { Fig 1b: Liver of rat from group } 2 \\
\text { showing the normal histological } \\
\text { structure of hepatic lobule (H \& E } \\
\text { X 400). }\end{array}$ & $\begin{array}{l}\text { Fig 1c: Liver of rat from group } 3 \\
\text { showing the normal histological } \\
\text { structure of hepatic lobule (H \& E } \\
\text { X 400). }\end{array}$ \\
\hline
\end{tabular}


